\title{
Ear canal collapse prevalence and associated factors among users of a center of prevention and rehabilitation for disabilities
}

Elisana Costa Dourado(1) Ana Paula Corona ${ }^{(2)}$

Silvia Ferrite ${ }^{(2)}$

(1) Centro Estadual de Prevenção e Reabilitação de Deficiências - CEPRED

- Salvador, Bahia, Brazil.

(2) Universidade Federal da Bahia - UFBA Salvador, Bahia, Brazil.

Completion work of Lato Sensu Post

Graduate Program in the Course of Speech, Language and Hearing Sciences of the

União Metropolitana de Educação e Cultura

- UNIME - Lauro de Freitas (BA), Brasil.

Conflict of interest: Nonexistent

Received on: July 18, 2017

Accepted on: September 21, 2017

Mailing address:

Elisana Costa Dourado

Rua das Patativas, 309, Edifício Costa do Imbuí, Apartamento 1002, Imbuí

CEP 41720100 - Salvador, Bahia, Brasil

E-mail: lisfono@yahoo.com.br

\section{ABSTRACT}

Purpose: to investigate the prevalence of the ear canal collapse when using supra-aural earphones and to verify if this event is influenced by sex, age, color of the skin and prominent ear.

Methods: the collapse was assessed by a visual inspection after the positioning of a detached cushion, pressured against the external ear.

Results: a total of 436 individuals, aged 3 to 97 years, participated in the study. Ear canal collapse was observed in $11.4 \%$ of the subjects, being mostly bilateral (90.0\%). The prevalence ranged from $6.3 \%$ to $36.6 \%$ across age groups. Males, aged 65 years or above and presence of prominent ear were independently identified as associated factors for the occurrence of ear canal collapse $(p<0.05)$. Despite a higher prevalence for those self-identified as white skinned when compared to non-whites, the difference was not statistically significant.

Conclusion: the ear canal collapse, when supra-aural earphones are used, is more likely to occur in men, in elderly people, and among those with prominent ears. The prevalence of the event in this population raises the necessity of a careful examination, previous to any evaluation using supra-aural earphones.

Keywords: Ear Canal; Audiometry; Hearing Loss; Diagnostic Errors; Prevalence 


\section{INTRODUCTION}

Despite technological advances, conventional audiological assessment remains the most widely used among the set of tests available for hearing evaluation. Although apparently simple, its use requires a great deal of care, clinical reasoning, and good judgment in decision making, to avoid errors in the results ${ }^{1,2}$. One of the main concerns relates to the possibility of an external acoustic meatus (EAM) collapse when supra-aural headphones are positioned. These headphones exert pressure on the auricular pavilion ${ }^{3-5}$ that in certain cases, when provoking deformation of its natural anatomical position, promotes EAM closure via constriction of its walls. This phenomenon causes acoustic energy reduction for all airborne sounds ${ }^{4,5}$, and consequently diminishes auditory perception, altering the results of threshold tests such as tonal audiometry ${ }^{4-7}$ or electrophysiological threshold testing ${ }^{8,9}$. It can also affect some suprathreshold procedures, such as contralateral acoustic reflex research ${ }^{5}$. In threshold tone audiometry specifically, the collapse of the external acoustic meatus can alter airway thresholds, resulting in a spurious conductive component of hearing loss, from 5 to $50 \mathrm{~dB}$, predominantly affecting high frequencies ${ }^{6}$. Errors in audiological diagnosis resulting from collapse interference can be avoided by prior identification of vulnerable cases, allowing the use of appropriate techniques to keep the auditory canal open ${ }^{5,6,10-13}$.

Several studies indicate the elderly to be most prone to the occurrence of the phenomenon 10,13-16. Nevertheless, the problem has also been identified in other age groups $4,5,14,17$. The likelihood of EAM collapse induced by mechanical pressure on the auricular pavilion, is related to individual anatomical characteristics. Consequently, the distribution of the event in the population can be differentiated among certain subgroups. This study aimed at investigating the prevalence of EAM collapse and determining whether the occurrence of this event is influenced by factors such as gender, age, skin color, and protruding ears.

\section{METHODS}

This study was examined and approved by the Ethics Committee of the União Metropolitana de Educação e Cultura - UNIME, under $n^{\circ} 175006 / 2005-21$. The study population comprised all individuals who attended from February to May 2006, a scheduled session in one of the evaluation rooms of a state referral center for the prevention and rehabilitation of disabilities. Those equal to or greater than three years old, without restriction of gender or hearing condition, were eligible, excluding those with EAM obstruction, afflictions, or malformations of the external ear, except for protruding ears.

All eligible individuals who agreed to participate in the study, through the signing of the Informed Consent form, underwent collapse research, conducted in a standardized way by positioning of a single headphone cushion, Telephonics model 510C017-1, pressed against the auricular pavilion, while respecting the natural conditions of the audiological clinic routine. The cushion was positioned manually by the examiner. The central hole, a space corresponding to the normal earpiece location, allowed visualization of the EAM walls. Collapse was considered to have taken place when complete closure of the acoustic meatus occurred during the procedure. If the walls approached, with a marked reduction of the auditory canal passage, but without constituting full occlusion, this was classified as EAM narrowing. To facilitate visualization, the light source from an otoscope was used.

The covariates analyzed in the study were gender, age, color of the skin, and the presence of protruding ears. Age was categorized into five groups: children ( 3 to 12 years), adolescents and young adults (13 to 39 years), adults (40 to 64 years), and two categories among the elderly (65 to 74,75 to 97 years). The color of the skin was categorized by the subjects themselves as white, brown, mulatto, black, or other; later simplified to whites and non-whites. The presence of protruding ears was defined based on the examiner's observation, as an angle greater than $30^{\circ}$ between the auricular pavilion and the skull, occurring due to concha increase or lateralization, and/or a lack of adequate folding of the antihelix ${ }^{18}$.

For analysis, the prevalence of collapse and narrowing was estimated in the study population, and characteristics related to laterality were identified. The distribution of the main event, bilateral EAM collapse, was analyzed according to the categories of covariates. Based on the results obtained from the various age groups, a cut-off point was established to create a dichotomous variable, aggregating the first three age groups (who showed similar prevalence), and the two elderly age groups, who differed from the others. Prevalence differences between men and women, among the age groups, between white and non-white, and between those with and without a protruding ear, were compared, estimating the corresponding prevalence ratios (PR). The statistical analysis was 
based on confidence intervals $(\mathrm{Cl})$ estimated by the Mantel-Haenszel method for an alpha of 0.05. As a complementary statistic, the $p$-values for the observed differences were calculated, adopting $p \leq 0.05$ to indicate statistical significance. The data were analyzed using SAS version 8.0.

\section{RESULTS}

The final study population consisted of 436 individuals, aged between 3 and 97 years, mean age 41.3 years $(S D=24.6)$, mostly female $(59.6 \%)$ and non-white (84.2\%). A small portion had protruding ears (2.5\%). The prevalence of bilateral EAM collapse in this population was estimated at $10.3 \%$, reaching $11.4 \%$ when considering also unilateral presentations. Among the 50 individuals with collapse, $90.0 \%$ presented with the condition bilaterally. All unilateral presentations were accompanied by contralateral EAM narrowing. The narrowing condition, in turn, was observed in a similar proportion in the population (Table 1). The occurrence of the event was slightly higher for the right ear (11.4\%) when compared to the left (10.3\%), but this did not constitute a statistically significant difference.

Table 1. Prevalence of collapse and narrowing of the external acoustic meatus when using supra-aural earphones, observed in the study population $(\mathrm{N}=436)$

\begin{tabular}{ccc}
\hline Observed Condition & $\mathbf{n}$ & Prevalence \\
\hline Bilateral collapse & 45 & 10.3 \\
RE collapse + LE narrowing & 5 & 1.1 \\
LE collapse + RE narrowing & 0 & - \\
Bilateral narrowing & 36 & 8.3 \\
RE narrowing + normal LE & 6 & 1.4 \\
LE narrowing + normal RE & 3 & 0.7 \\
\hline
\end{tabular}

$\mathrm{RE}=$ right ear; $\mathrm{LE}=$ left ear

Figure 1 shows the prevalence of bilateral EAM collapse among users, according to age. The occurrence of collapse was stable among the first three groups, with an increase in prevalence among the elderly, especially in the older age group.

The prevalence of EAM collapse in this population, according to covariate categories, magnitude of association (PR) and their respective $95 \% \mathrm{Cl}$, are presented in Table 2. Males, age 65 years or older and presence of protruding ears were identified as factors associated with the occurrence of the event. Although the prevalence of collapse was higher among users who reported white skin, the difference was not statistically significant, compared to non-white patients. 


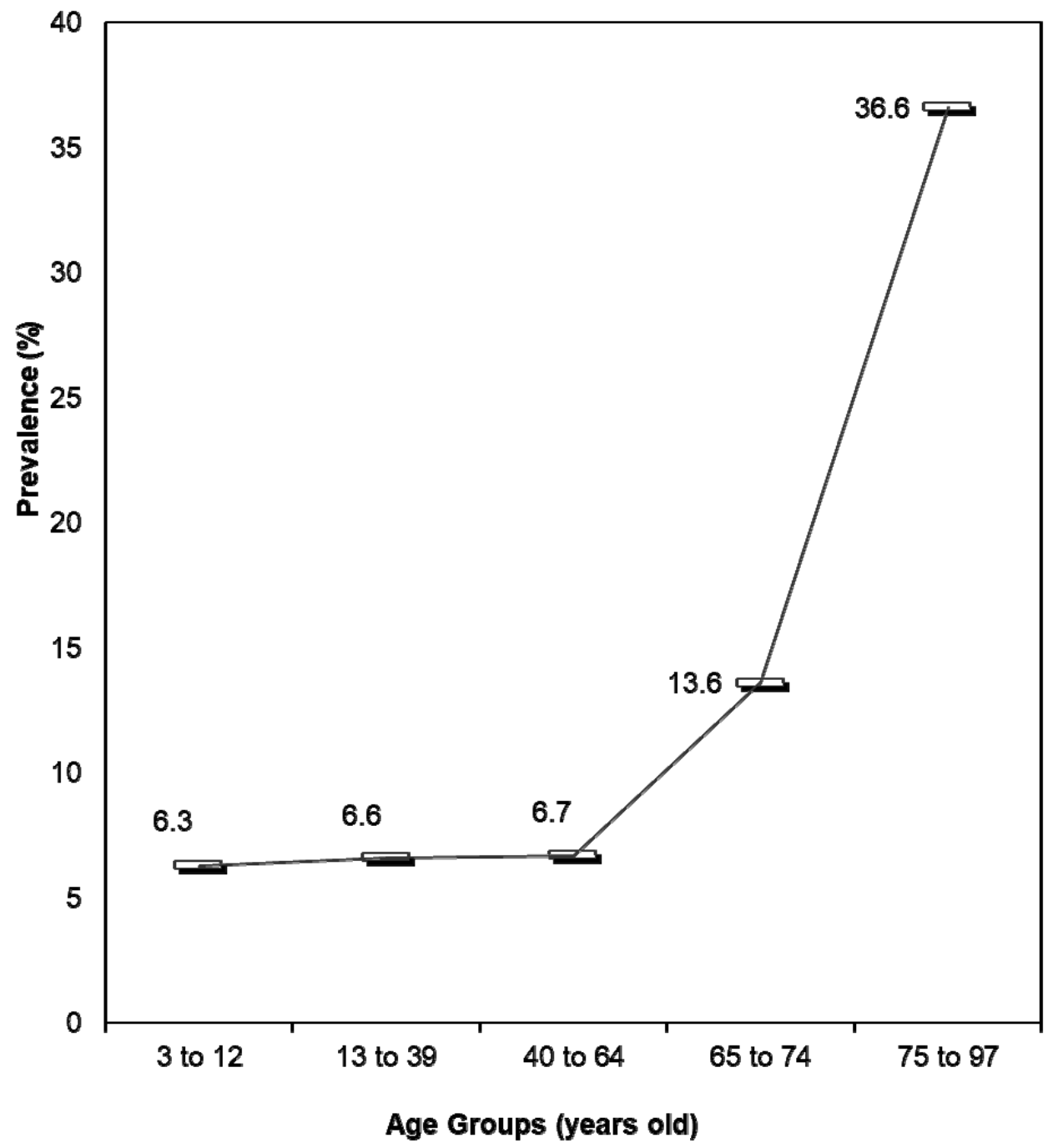

Figure 1. Prevalence of external acoustic meatus collapse, according to age, in the study population ( $N=436)$

Table 2. Prevalence, prevalence ratio and respective confidence intervals for the association between study covariables and external acoustic meatus collapse in the study population $(\mathrm{N}=436)$

\begin{tabular}{cccc}
\hline Variables & Prevalence (\%) & $\mathbf{P R}^{\mathbf{a}}$ & $\mathbf{C l}^{\mathbf{b}} \mathbf{9 5 \%}$ \\
\hline Sex* & & & \\
Male & 16.5 & 2.7 & $(1.5-4.8)$ \\
Female & 6.2 & & \\
\hline Age* & & & \\
3 to 64 years & 6.6 & 3.5 & $(2.0-6.0)$ \\
65 to 97 years & 23.0 & & \\
\hline Skin color & 14.5 & 1.5 & \\
White & 9.5 & & $(1.8-2.9)$ \\
Not white & 36.4 & 3.8 & \\
\hline Prominent ear* & 9.7 & & \\
Yes & &
\end{tabular}

${ }^{\text {aPR }}=$ prevalence ratio; ${ }^{\circ} \mathrm{Cl}=$ confidence interval calculated by the Mantel-Haenszel method;

${ }^{*}$ Chi-square, statistically significant differences $(p<0.05)$ 


\section{DISCUSSION}

The results of this study suggest a greater chance of EAM collapse during audiological procedures with supra-aural headphones when the evaluated individuals are men, when they are 65 years of age or older, or when they present protruding ears. Although no statistical significance was obtained, there was a tendency for the event to occur more often among whites compared to nonwhites.

Some definitions of EAM collapse include near approach of the ear canal walls to each other, even without closure of the auditory canal $\left.\right|^{4,6,10,14}$. A marked reduction in the canal airway, without occlusion of the EAM, was defined in this study as "narrowing". The term "collapse" was restricted to the condition of total occlusion, in agreement with definitions presented by other authors ${ }^{4,11}$. This terminological option is based on the potential differences between the effects of an EAM collapse and narrowing in the results of audiological exams. It is believed that the occurrence of erroneous

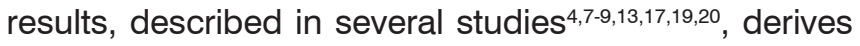
predominantly from the complete phenomenon, that is, complete EAM collapse. This is a topic that should continue to be discussed among audiologists, since a consensus in the definition is essential for precision in clinical conduct. A clear distinction between the two conditions would be helpful for research, facilitating comparisons between studies by reducing methodological bias in definition.

The prevalence of bilateral and unilateral collapse among individuals aged 3-97 years, in the study population was $10 \%$ and $11 \%$, respectively. Comparison of these values with those presented by other studies is hampered by differences in age composition among the investigated populations, since age may significantly increase or decrease prevalence ${ }^{13,14,20}$. Like the others, this study is not representative of the general population, having as subjects the population who attended an audiological clinic with hearing complaints.

The narrowing condition was identified in a similar proportion of the evaluated individuals, as complete collapse. It is possible that people who currently present a marked reduction of the auditory canal may have a greater chance of showing collapse with advancing age. However, only longitudinal studies could test this hypothesis.

As to laterality, previous studies indicate that collapse can occur unilaterally or bilaterally ${ }^{10,14}$, and there have been no findings suggesting that either ear has a greater chance of being affected ${ }^{6}$. The results of the present study are consistent with both statements. We emphasize that the predominance of bilateral presentation, identified in $90 \%$ of the cases, and the narrowing of the contralateral EAM, observed in all unilateral cases, should alert an examiner who has identified collapse in the first ear submitted for examination.

The analysis of the influence of age on the occurrence of EAM collapse in this population revealed a similar prevalence among the three young age groups, consisting of children, adolescents, and adults. However, the likelihood of the event increased progressively for the two elderly groups, reaching more than a third of individuals aged 75 years or older. For the association analysis, the elderly group (age $\geq 65$ years) was compared with the complementary group, and a statistically significant positive association was identified. The greater chance of occurrence of collapse in the elderly population corroborates the results of several studies ${ }^{10,13-15,20}$. A reduction in elasticity of the external auditory canal due to cutaneous and cartilaginous flaccidity is a plausible explanatory hypothesis ${ }^{21,22}$. No greater prevalence among children was identified, as opposed to previous findings ${ }^{14}$, which may be related to the non-inclusion of children under 3 years of age, in the present study.

Contrary to results obtained by other authors ${ }^{13,14}$, which did not identify a difference in the occurrence of collapse between genders, this study found a significantly higher prevalence among male users, calculated as 2.7 times the prevalence found among women. In other words, the occurrence of collapse in males was $170 \%$ higher than that observed in females. The explanation is unknown, but may be related to some anatomical features that are more common in males. For example, of the cases with protruding ears in this study, $72.7 \%$ were men. It is possible that men generally have a greater angle between the ear and the skull than women, even if it is not so pronounced as to be classified as a distinction.

Only eleven subjects in this study presented the characteristic of protruding ears. Hence, it was possible to verify a statistically significant association with the EAM collapse, and the prevalence ratio (3.8) indicates the strength of this association. We should emphasize that the small size of the group inevitably results in an increase in the $\mathrm{Cl}$. A greater likelihood of individuals with protruding ears presenting collapse was also reported in an earlier study ${ }^{10}$. A greater angle between the auricular pavilion and the head implies a 
more marked modification of the natural anatomical position of the pavilion when supra-aural headphones are positioned, contributing to EAM collapse.

Although the prevalence of the event among white users was $50 \%$ higher than among non-whites, the association was not statistically significant and could not be confirmed. It is possible that the use of selfreported skin color data brought about problems in the correct classification of individuals, as the small portion of whites may have reduced the power of the analysis. Consequently, we recommend that the hypothesis be investigated in new studies conducted with a larger sample of white individuals, with skin color classified by trained personnel. To our knowledge, no previous studies have analyzed the relationship between skin color and EAM collapse.

In identifying an ear that will potentially show collapse during a procedure with supra-aural headphones, the use of a single headphone cushion can be a facilitator, because of the similarity between the mode of verification and the examination itself. However, the event can easily be identified even without the use of instruments, by pressing the fingers on the auricular pavilion against the mastoid bone without applying force in any other direction, as this would not be consistent with the pressure exerted by the headphones. It is recommended to use a light source such as an otoscope, especially to check the condition in dark-skinned individuals. Several studies describe and quantify the effects of collapse on various types of audiological tests, and indicate strategies for managing the problem, consequently avoiding errors in audiological diagnosis $47,10,11,13,16,17,19,20,23$.

The study presents valuable features such as differentiation in the operational definitions of collapse and narrowing, the use of the single cushion in a standardized procedure for EAM visual inspection, and a suitable sample size for the analysis of factors associated with the studied event. Among the research limitations, the absence of a precise instrument for protruding ear classification should be considered, which may have led to the underestimation of cases by the identification of only those with the most prominent characteristics; the fact that the visual inspection was not subjected to replication by a second observer; and the self-reporting of skin color, although identification by the interviewer is also potentially subject to classification biases. We recommend that future studies consider the results presented here, both positive and negative, as a contribution to the advancement of knowledge in the area.

\section{CONCLUSION}

This study presents evidence that EAM collapse, when using supra-aural headphones, is an event with greater prevalence among men, among the elderly, and among those with protruding ears. Even the lowest prevalence estimated in the age groups of the study population suggests that at least one in 20 individuals may present with this condition, in the audiological clinic. Thus, constant attention by professionals to the possibility of collapse is essential to avoid errors in audiological diagnosis, which may in turn result in subsequent inadequate remedies. Consequently, knowledge of the prevalence of this event alerts us to the need for careful verification, prior to any assessment or procedure with supra-aural phones, in all population groups.

\section{REFERENCES}

1. Almeida BP, Menezes PDL, Andrade KCLD, Teixeira CF. Positioning of earphones and variations in auditory thresholds. Braz J Otorhinolaryngol. 2015;81(6):642-6.

2. Zwislocki J, Kruger B, Miller JD, Niemoeller AF, Shaw EA, Studebaker G. Earphones in audiometry. J Acoust Soc Am. 1988;83(4):1688-9.

3. Mello LAD, Silva RAMD, Gil D. Test-retest variability in the pure tone audiometry: comparison between two transducers. Audiol. Commun. Res. 2015;20(3):239-45.

4. Sauer RC, Ford CN. Collapse of the ear canal during masking for bone conduction. Am $\mathrm{J}$ Otol. 1986;7(1):51-4.

5. Campos CF, Cruz MS, Feniman MR. Colabamento do meato acústico externo: relato de um caso. Pró-Fono R. Atual. Cientif. 2004;16(1):95-100.

6. Toniosso S, Redondo MC, Lopes Filho O. Alterações dos limiares auditivos causados pelo colabamento de meato acústico externo. Rev Bras Otolaringol. 2000;66(6):652-8.

7. Rizo SR. Correcting for ear canal collapse during audiometry. Ear Hear. 1983;4(5):255-7.

8. Hosford-Dunn H, Runge CA, Hillel A, Johnson SJ. Auditory brain stem response testing in infants with collapsed ear canals. Ear Hear. 1983;4(5):258-60. 
9. Hood LJ. Clinical applications of the auditory brainstem response. San Diego: Singular Publishing Group; 1998.

10. Jerger J, Jerger S. Colabamento do conduto auditivo externo. In: Jerger J, Jerger $S$ (orgs). Alterações auditivas: um manual para avaliação clínica. Rio de Janeiro: Atheneu; 1989. p. 29-34.

11. Pearlman RC. Preventing collapsed of external auditory meatus during audiometry. Arch Otolaryngol. 1975;101(11):686-8.

12. Frazza MM, Caovilla HH, Munhoz MSL, Silva MLG, Ganança MM. Audiometria tonal e vocal. In: Munhoz MSL, Caovilla HH, Silva MLG, Ganança MM (orgs). Audiologia clínica. São Paulo: Atheneu; 2000. p. 49-71.

13. Randolph LJ, Schow RL. Threshold inaccuracies in an elderly clinical population: ear canal collapse as a possible cause. J Speech Hear Res. 1983;26(1):54-8.

14. Campos CF, Cruz MS, Feniman MR. Colabamento do meato acústico externo: ocorrência em pacientes submetidos à avaliação audiológica e otorrinolaringológica no CEDALVI - USP/Bauru. J Bras de Fonoaudiol. 2004;18(5):17-9.

15. Marangoni AT, Scharlach RC, Silveira MRM, Calais LL, Gil D. Insert earphones: application to avoid collapse of the external auditory canal. Rev Soc Bras Fonoaudiol. 2012;17(1):61-5.

16. Oda DTM, Marangoni AT, Gil D. Insertion and supra-aural earphones: audiological assessment in the elderly. Rev. CEFAC. 2014;16(1):31-8.

17. Mohamad A, Algarni M. Bilateral conductive hearing loss due to collapsed ear canals in a 35 years old female. J Otolaryngol ENT Res. 2016;4(4):110.

18. Ribeiro FQ. Otoplastia: revisão da literatura e descrição de técnica própria. Acta Otorrinolaringol. 2005;23(2):6-14.

19. Mahoney CF, Luxon LM. Misdiagnosis of hearing loss due to ear canal collapse: a repot of two cases. J Laryngol Otol. 1996;110(6):561-6.

20. Schow RL, Goldbaum DE. Collapsed ear canals in the elderly nursing home population. J Speech Hear Disord. 1980;45(2):259-67.

21. Mitre El. Aspectos otorrinolaringológicos do idoso. In: Suzuki HS (org). Conhecimentos essenciais para atender bem o paciente idoso. São José dos Campos: Pulso; 2003. p. 20-6.

22. Silva APR, Blasca WQ, Lauris JRP, Oliveira JRM. Correlation between the characteristics of resonance and aging of the external ear. CoDAS. 2014;26(2):112-6.

23. Amaral LKM, Ferreira FHV, Dias FAM. Utilização de uma manobra específica para evitar alterações dos limiares auditivos causadas pelo colabamento do meato acústico externo. Rev CEFAC. 2008;10(3):409-15. 